\title{
Article \\ Real-World Testing of the Self Grasping Hand, a Novel Adjustable Passive Prosthesis: A Single Group Pilot Study
}

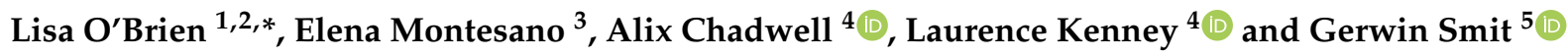 \\ 1 Department of Occupational Therapy, Faculty of Medicine, Nursing and Health Sciences, Monash University, \\ Melbourne 3199, Australia \\ 2 Department of Nursing and Allied Health, Swinburne University of Technology, Hawthorn 3122, Australia \\ 3 Caulfield Hospital, Melbourne 3162, Australia; E.Montesano@alfred.org.au \\ 4 Human Movement and Rehabilitation Research Group, School of Health \& Society, University of Salford, \\ Manchester M6 6PU, UK; A.E.A.Chadwell1@salford.ac.uk (A.C.); L.P.J.Kenney@salford.ac.uk (L.K.) \\ 5 Department of BioMechanical Engineering, Delft University of Technology, 2628 CD Delft, The Netherlands; \\ g.smit@tudelft.nl \\ * Correspondence: ljobrien@swin.edu.au
}

Citation: O'Brien, L.; Montesano, E.; Chadwell, A.; Kenney, L.; Smit, G. Real-World Testing of the Self Grasping Hand, a Novel Adjustable Passive Prosthesis: A Single Group Pilot Study. Prosthesis 2022, 4, 48-59. https://doi.org/10.3390/ prosthesis4010006

Academic Editor: Andreas Otte

Received: 23 December 2021

Accepted: 2 February 2022

Published: 8 February 2022

Publisher's Note: MDPI stays neutral with regard to jurisdictional claims in published maps and institutional affiliations.

Copyright: (C) 2022 by the authors. Licensee MDPI, Basel, Switzerland. This article is an open access article distributed under the terms and conditions of the Creative Commons Attribution (CC BY) license (https:// creativecommons.org/licenses/by/ $4.0 /)$.

\begin{abstract}
Background: This study investigated the feasibility of conducting a two-week "realworld" trial of the Self Grasping Hand (SGH), a novel 3D printed passive adjustable prosthesis for hand absence; (2) Methods: Single-group pilot study of nine adults with trans-radial limb absence; five used body-powered split-hooks, and four had passive cosmetic hands as their usual prosthesis. Data from activity monitors were used to measure wear time and bilateral activity. At the end of the two-week trial, function and satisfaction were measured using the Orthotics and Prosthetics Users' Survey Function Scale (OPUS) and the prosthesis satisfaction sub-scales of the Trinity Amputations and Prosthesis Experience Scale (TAPES). Semi-structured interviews captured consumer feedback and suggestions for improvement; (3) Results: Average SGH wear time over 2 weeks was $17.5 \mathrm{~h}$ (10\% of total prosthesis wear time) for split-hook users and $83.5 \mathrm{~h}$ (63\% of total prosthesis wear time) for cosmetic hand users. Mean satisfaction was 5.2/10, and mean function score was 47.9/100; (4) Two-week real-world consumer testing of the SGH is feasible using the methods described. Future SGH designs need to be more robust with easier grasp lock/unlock.
\end{abstract}

Keywords: prosthetic; passive; adjustable; hand; 3D printing; trans-radial

\section{Introduction}

Unlike active upper-limb prostheses, passive devices do not provide the user with continuous control over grasping movement. They may, however, improve function by assisting the intact hand/arm with bimanual activities [1]. One in three people with trans-radial upper limb absence chooses to use a passive hand as their primary prosthesis [2], with older adults [3] and those with congenital limb absence more likely to choose them [4]. The primary reasons for this are their life-like appearance and increased comfort, with users prepared to sacrifice a degree of function to achieve this [4,5]. Additionally, passive prostheses are generally lighter than active devices, because they contain no motors and few mechanical systems.

To close the gap in function, some passive hands include multi-positional joints; these are termed adjustable passive prostheses [2]. Using the intact hand, or by interacting with the environment, the user can position joints to make it easier to hold, stabilise, or carry an object. A recent evidence review of passive prosthetic hands and tools recommended research focusing on adjustable hands, as they offer the most potential for improvement [2]. Specifically, suggestions included developing and testing models 
with articulating fingers, adjustable grip force, and/or faster and easier control of grasp/release mechanisms.

The "Self Grasping Hand" (SGH) was recently developed at Delft University of Technology, Netherlands, to address the aforementioned need for a better adjustable hand $[6,7]$. This adjustable passive hand was designed for adults with hand absence and can be mounted on the wrist connector of the user's existing socket. It is fabricated from a combination of 3D-printed components, laser-cut steel, and springs and is lightweight $(<300 \mathrm{~g})$. It requires no batteries, motors, or cables and operates using a linkage mechanism that mimics the natural tenodesis grasp/release pattern, i.e., the further the wrist extends, the more the fingers flex. To activate the grasping mechanism, the user achieves wrist extension by either pushing the palm against an object (such as a bicycle handle) or pushing an object into the palm. Grasp remains locked by a ratchet system until the user pushes the release button on the dorsal surface, then disengages the ratchet by pushing the wrist slightly into extension. The thumb is rigid but can be pivoted between radial abduction and opposition to the index finger (see Figure 1). It is designed to be worn with a skin colour-matched PVC or silicone commercially available size 71/4 " glove to improve grip and aesthetics [6,7].
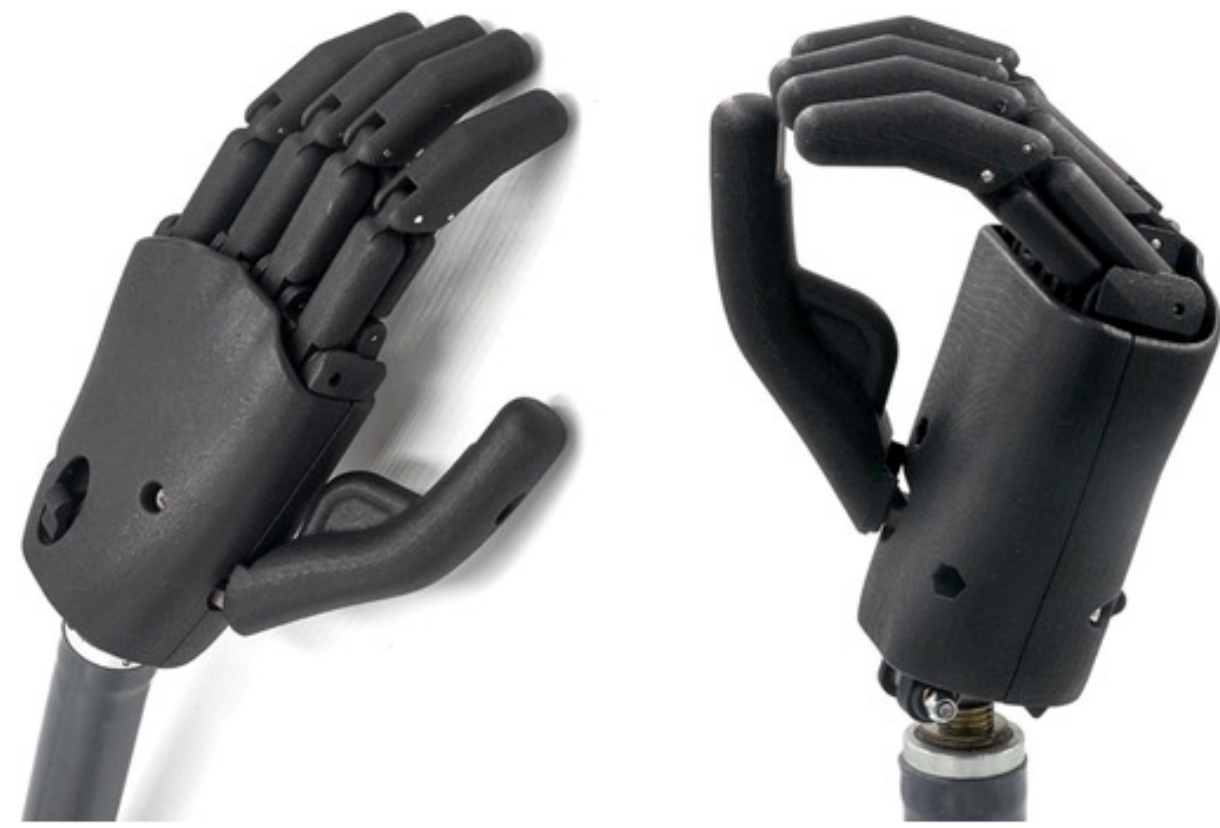

Figure 1. The Self Grasping Hand without cosmetic glove applied.

Initial laboratory testing of the SGH, with healthy anatomically intact adult volunteers performing activities of daily living using the SGH fitted to a prosthesis simulator, was promising, indicating that it was used more frequently than a conventional passive hand [6,7]. Further lab-based testing, also with anatomically intact adult volunteers performing the Southampton Hand Assessment Procedure (SHAP), quantified the amount of contralateral hand involvement in the operation of the SGH [8]. They found that the percentage of task time where the user was reliant on the contralateral hand remained relatively unchanged $(\sim 30 \%)$ with practice. The authors recommended evaluating the impact of reliance on the contralateral limb in day-to-day life in a sample of prosthesis users using the SGH over an extended period of time.

The pilot study presented here was conducted to explore whether the SGH was acceptable and useful for adults with trans-radial limb absence who currently use either a cosmetic hand or body-powered prostheses and to compare its performance with their existing prosthesis. We asked participants to use the SGH over two weeks in their own environment so that we could capture prosthesis use during typical self-care, work, and leisure 
patterns. This also enabled us to collect "real-world" data from participants regarding the utility and robustness of the SGH to inform improvements to the design prior to testing future prototypes. The prosthesis users could, together with the prosthetist, select whether or not they wanted to wear a glove over the hand, and they could select a standard glove material (PVC or silicone). No tests or research were performed on glove development, as this was out of the scope of the study.

Our secondary aim was to determine whether a larger study was feasible for testing future models and whether our proposed method for objectively measuring prosthesis wear and use was acceptable and reliable and yielded useful data.

\section{Results}

\subsection{Participants}

Five male and four female adults participated (mean age: 45.9 years, range: 19-62 years). Table 1 summarizes demographic, clinical, and functional characteristics. One participant was a quadruple amputee, and one was additionally missing the index and middle fingers from their contralateral limb. All except two (one on maternity leave and one on sick leave) were in paid employment or full-time studies at the time of the trial.

Table 1. Demographic and clinical characteristics $(\mathrm{N}=9)$.

\begin{tabular}{|c|c|}
\hline \multicolumn{2}{|l|}{ Characteristics } \\
\hline Sex, n (\%) & \\
\hline Male & $5(55.5 \%)$ \\
\hline Female & $4(44.5 \%)$ \\
\hline Age, years, mean $(\mathrm{SD})^{1}$ & $45.9(14.9)$ \\
\hline Range & $19-62$ \\
\hline Years since amputation, mean (SD) & $31.1(21.5)$ \\
\hline Range & $0.75-62$ \\
\hline Years using current prosthesis, mean (SD) & $8.4(1.17)$ \\
\hline Range & $0.33-45$ \\
\hline Cause of amputation, $\mathrm{n}(\%)$ & \\
\hline Congenital & $5(55.5 \%)$ \\
\hline Injury & $2(22.2 \%)$ \\
\hline Infection & $2(22.2 \%)$ \\
\hline Type of prosthesis used (at the time of testi & \\
\hline Passive & $4(44.5 \%)$ \\
\hline Body-powered & $5(55.5 \%)$ \\
\hline Occupation category, $\mathrm{n}$ & \\
\hline Manager & 1 \\
\hline Professional & 1 \\
\hline Technician/Trade & 2 \\
\hline Community and personal service & 1 \\
\hline Clerical & 1 \\
\hline Machinery operator/driver & 1 \\
\hline University student & 1 \\
\hline Home duties & 1 \\
\hline
\end{tabular}

${ }^{1} \mathrm{SD}=$ standard deviation.

\subsection{Prosthesis Wear Time}

Data from most participants showed periods where one or other prosthesis was worn but the monitor on the anatomical wrist was removed (total $430.62 \mathrm{~h}$ out of $902.59 \mathrm{~h}$ of prosthesis wear time). Figure 2 shows the wear time for SGH and usual prostheses for the six participants from whom we were able to collect data from all three monitors. The cosmetic prosthesis users wore the SGH for a total of $250.57 \mathrm{~h}$ (compared to their own 
prostheses, which they wore for $124.98 \mathrm{~h}$ ), whilst the body-powered prosthesis users wore the SGH for a total of $52.57 \mathrm{~h}$ (compared to $474.47 \mathrm{~h}$ for their own devices).
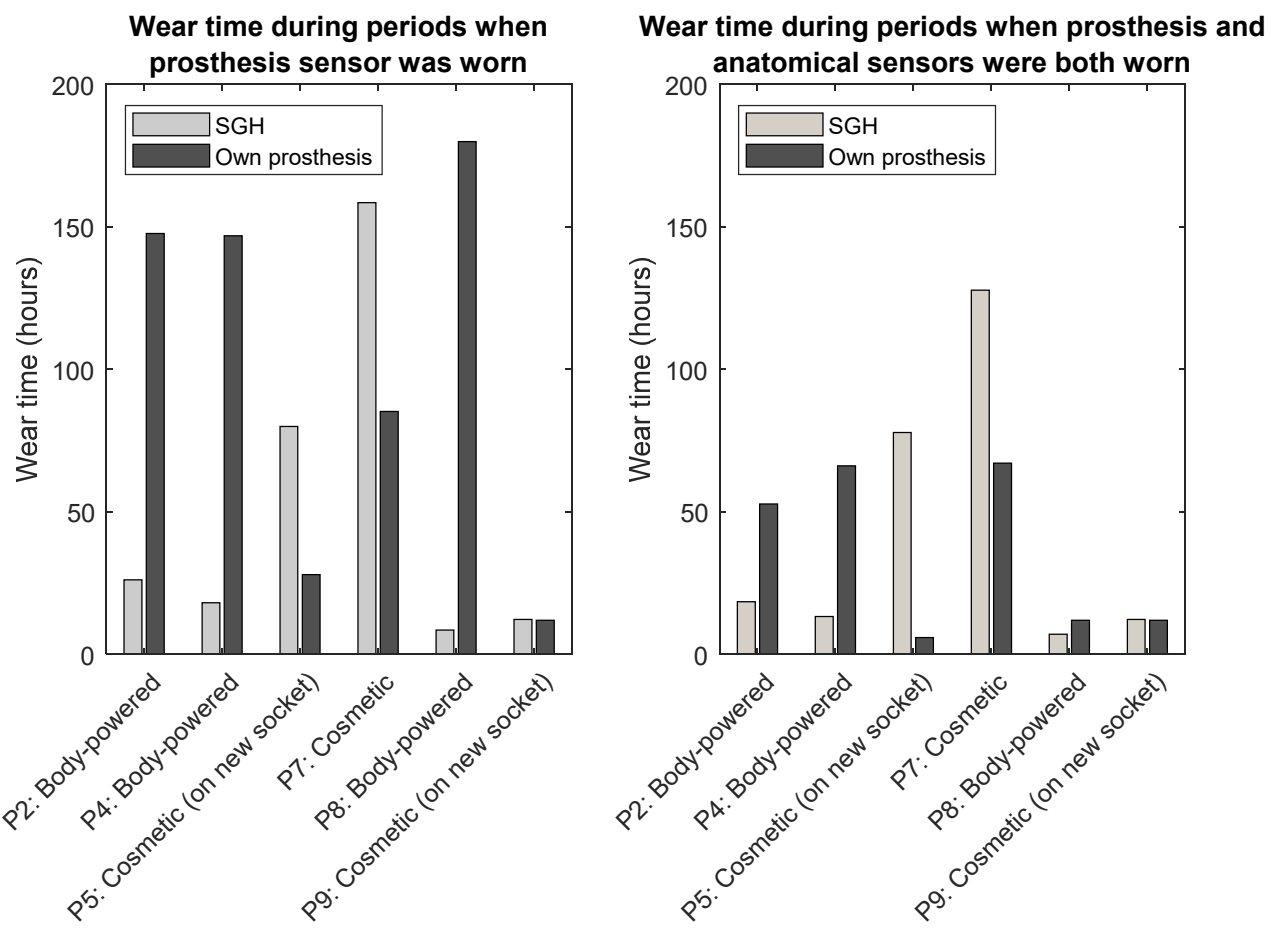

Figure 2. Prosthesis wear time (hours) for participants with full datasets. P: participant; SGH: Self Grasping Hand.

During periods when the participant wore both the anatomical monitor and one of the prosthesis monitors, we calculated the percentage reliance on the anatomical arm for each $60 \mathrm{~s}$ epoch. As a summary measure, the median reliance was then calculated for each participant [9] (Figure 3). The body-powered prosthesis users were generally more reliant on the anatomical arm when wearing the SGH (mean: 77.75\%; SD: 0.99\%) than when using their own prosthesis (mean: 74.21\%; SD: 4.32\%), whilst the cosmetic prosthesis users showed an improved level of symmetry when using the SGH $(80.42 \%$; SD: 6.93\%) compared to their own prosthesis (91.49\%; SD: $11.11 \%$ ).

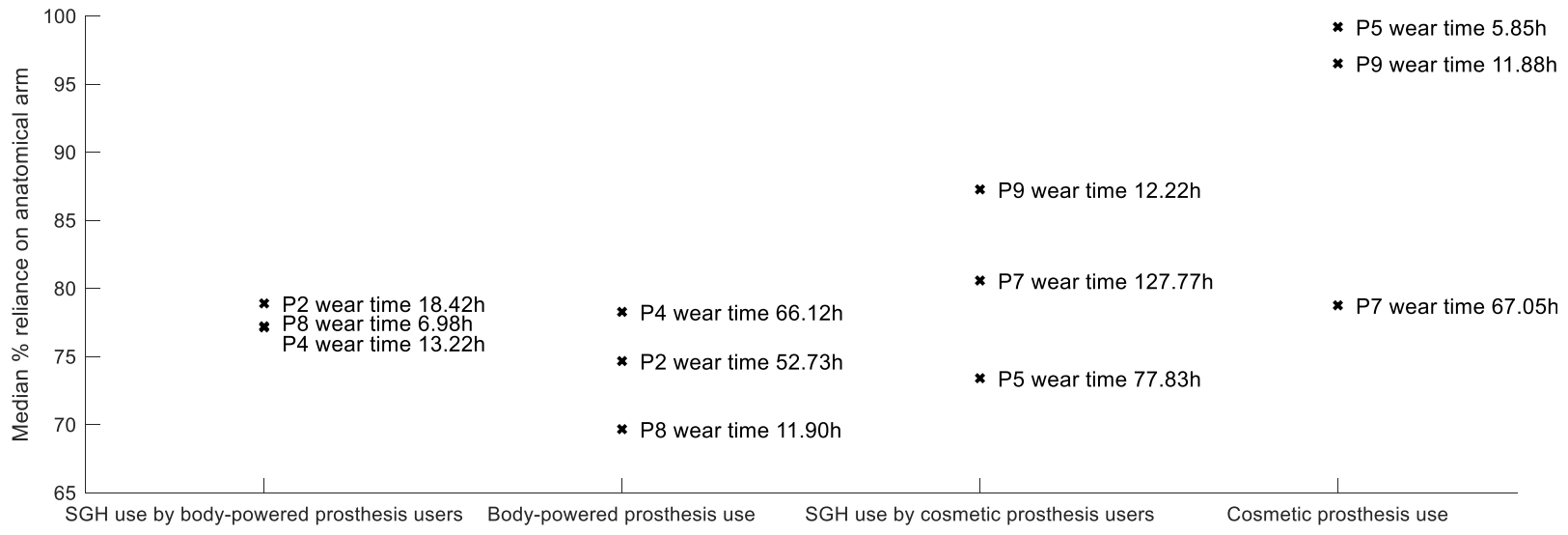

Figure 3. Median percentage reliance on the anatomical arm. 
Body-powered prosthesis users tended to wear the SGH for the first two to three days of the trial then revert to their usual prosthesis in order to complete their work or daily living tasks. All of this sub-group were in employment requiring frequent moderately strenuous bimanual work. In contrast, passive cosmetic hand users persisted with the SGH for the full trial period.

\subsection{Patient-Reported Outcome Measures}

Participants were instructed to complete the OPUS upper-extremity functional status, specifically focusing on the performance of the SGH. Frequency distribution and mean values for scores on the 23 items are presented in Table 2. The mean Rasch converted score was 47.9/100 \pm 7.25 (range: 40.4-61.4). When stratified by usual prosthesis type, means were 45.8/100 for body-powered split hook users and 50/100 for cosmetic hand users.

Table 2. Frequency distribution and mean values for the score of the 23 upper extremity functional status items.

\begin{tabular}{|c|c|c|c|c|c|c|c|c|}
\hline Item & $\begin{array}{l}\text { Not } \\
\text { Able }\end{array}$ & $\begin{array}{c}\text { Very } \\
\text { Difficult }\end{array}$ & $\begin{array}{l}\text { Slightly } \\
\text { Difficult }\end{array}$ & Easy & $\begin{array}{l}\text { Very } \\
\text { Easy }\end{array}$ & $\begin{array}{l}\text { N/A or } \\
\text { Missing }\end{array}$ & $\begin{array}{l}\text { Raw } \\
\text { Score } \\
\text { Mean } \\
\text { (SD) }^{2}\end{array}$ & $\begin{array}{c}\text { Using } \\
\text { SGH } \\
(\%)^{1}\end{array}$ \\
\hline 1. Wash face & 0 & 0 & 0 & 0 & 7 & 1 & $4.0(0)$ & $0.0 \%$ \\
\hline 2. Put toothpaste on brush and brush teeth & 1 & 0 & 2 & 2 & 3 & 0 & $2.8(1.4)$ & $50.0 \%$ \\
\hline 3. Brush/comb hair & 0 & 0 & 1 & 1 & 4 & 2 & $3.4(0.9)$ & $16.7 \%$ \\
\hline 4. Put on and remove t-shirt & 1 & 0 & 2 & 2 & 3 & 0 & $3.0(1.4)$ & $62.5 \%$ \\
\hline 5. Button shirt with front buttons & 1 & 0 & 3 & 1 & 1 & 2 & $1.8(1.6)$ & $0.0 \%$ \\
\hline 6. Attach end zipper and zip jacket & 4 & 0 & 2 & 0 & 0 & 2 & $0.8(1.1)$ & $66.7 \%$ \\
\hline 7. Put on socks & 1 & 0 & 1 & 3 & 2 & 1 & $3.2(0.8)$ & $28.6 \%$ \\
\hline 8. Tie shoelaces & 3 & 0 & 1 & 2 & 0 & 2 & $2.0(1.4)$ & $66.7 \%$ \\
\hline 9. Drink from a paper cup & 0 & 0 & 3 & 0 & 3 & 2 & $2.9(1.1)$ & $50.0 \%$ \\
\hline 10. Use fork or spoon & 3 & 0 & 0 & 1 & 2 & 2 & $2.2(2.0)$ & $66.7 \%$ \\
\hline 11. Cut meat with knife and fork & 4 & 0 & 2 & 1 & 0 & 1 & $1.2(1.3)$ & $85.7 \%$ \\
\hline 12. Pour from a $12 \mathrm{oz}$ can & 0 & 1 & 1 & 2 & 3 & 1 & $2.7(1.4)$ & $42.9 \%$ \\
\hline 13. Write name legibly & 0 & 0 & 0 & 2 & 5 & 1 & $3.6(0.5)$ & $0.0 \%$ \\
\hline 14. Use scissors & 2 & 0 & 2 & 1 & 1 & 1 & $2.2(1.3)$ & $28.6 \%$ \\
\hline 15. Open door with knob & 0 & 1 & 1 & 2 & 3 & 1 & $2.5(1.7)$ & $42.9 \%$ \\
\hline 16. Use a key in a lock & 1 & 0 & 0 & 1 & 6 & 0 & $3.3(1.4)$ & $12.5 \%$ \\
\hline 17. Carry laundry basket & 0 & 0 & 1 & 5 & 1 & 1 & $3.0(0.6)$ & $85.7 \%$ \\
\hline 18. Dial a touch-tone phone & 0 & 2 & 1 & 1 & 4 & 0 & $3.1(1.1)$ & $25.0 \%$ \\
\hline 19. Use a hammer and nail & 2 & 0 & 0 & 1 & 0 & 5 & $1.5(2.1)$ & $0.0 \%$ \\
\hline 20. Fold a bath towel & 0 & 0 & 0 & 4 & 1 & 3 & $2.8(1.9)$ & $80.0 \%$ \\
\hline 21. Open an envelope & 0 & 1 & 0 & 4 & 1 & 2 & $2.9(0.9)$ & $50.0 \%$ \\
\hline 22. Stir in a bowl & 1 & 0 & 3 & 1 & 0 & 3 & $2.0(1.1)$ & $60.0 \%$ \\
\hline 23. Put on and take off prosthesis & 0 & 0 & 3 & 3 & 3 & 0 & $3.0(0.9)$ & $0.0 \%$ \\
\hline
\end{tabular}

${ }^{1}$ Percentage performing activity with prosthesis is computed by excluding missing and "not able" responses.

${ }^{2}$ SD: standard deviation.

When asked to rate aspects of the SGH using the TAPES-R, mean scores were $2.17 / 3$ for aesthetics and $2.07 / 3$ for function, indicating that most were satisfied with these dimensions. Mean prosthesis satisfaction score was 5/10 (range: 3-8), with body-powered prosthesis users rating it slightly higher $(5.25 / 10)$ than passive users $(4.75 / 10)$. Participant raw scores are presented in Table 3.

In post-study interviews, all participants commented that the SGH release button was difficult to operate, and most (7/9) commented that the finger-to-thumb aperture was too small to grasp everyday objects, such as bottles or cups. Those who tried the hand with and without a cosmetic glove found that the glove increased the force required to initiate grasp, due to resistance over joints, and made the release button difficult to operate. Body-powered split-hook users commented that they were unable to perform their usual work duties with the SGH and that they are unlikely to find this type of hand useful to 
them. Suggestions for improvement were a motion-activated release button (to remove the need for the intact hand to operate this), a more curved thumb (to allow a rounded pinch grip), and a better fitting glove made from material that provides stronger grip across the palm and fingertips but enough flexibility to allow unimpeded motion of the finger joints.

Table 3. Scores for TAPES-R by participant.

\begin{tabular}{|c|c|c|c|c|c|c|c|c|c|}
\hline \multirow[b]{2}{*}{$\begin{array}{l}\text { SGH Aspects } \\
\text { (Maximum = 3) }\end{array}$} & \multicolumn{8}{|c|}{ Participant Number } & \multirow[b]{2}{*}{ Mean } \\
\hline & 1 & 2 & $3^{1}$ & 4 & $5^{1,2}$ & $7^{1}$ & 8 & $9^{1,2}$ & \\
\hline Colour & 2 & 3 & 2 & 2 & 3 & 2 & 2 & 2 & 2.3 \\
\hline Shape & 2 & 3 & 2 & 3 & 2 & 1 & 2 & 1 & 2.0 \\
\hline Appearance & 2 & 3 & 2 & 3 & 3 & 1 & 3 & 1 & 2.3 \\
\hline \multicolumn{3}{|c|}{ Aesthetics Subtotal } & & & & & & & 2.2 \\
\hline Weight & 2 & 3 & 3 & 3 & 2 & 2 & 2 & 1 & 2.3 \\
\hline Usefulness & 2 & 1 & 1 & 2 & 2 & 1 & 1 & 2 & 1.5 \\
\hline Reliability & 2 & 2 & 1 & 1 & 2 & 1 & 2 & 2 & 1.6 \\
\hline Fit & 2 & 3 & 2 & 3 & 3 & 3 & 3 & 2 & 2.6 \\
\hline Comfort & 2 & 1 & 2 & 3 & 3 & 3 & 3 & 2 & 2.4 \\
\hline \multicolumn{3}{|c|}{ Function Subtotal } & & & & & & & 2.1 \\
\hline $\begin{array}{l}\text { Overall Prosthesis } \\
\text { Satisfaction rating } \\
(\text { maximum }=10)\end{array}$ & 6 & 5 & 3 & 8 & 7 & 3 & 2 & 6 & 5.0 \\
\hline
\end{tabular}

${ }^{1}$ Participants whose usual prosthesis had a passive hand; ${ }^{2}$ participants for whom a new socket was fabricated.

\subsection{Adverse Events}

For three participants, the SGH required repair or replacement during the trial period. The thumb became detached from one hand after two days ( $\sim 6 \mathrm{~h}$ of wear) for participant 7 ; after returning to the clinic for repairs, the participant continued the trial. One or more 3D-printed internal components broke for two SGHs tested by participant 2. This occurred while familiarising himself with the operation of the hand, and he received a new hand prior to trial commencement. For participant 4, the ratchet mechanism jammed after two days ( $4 \mathrm{~h}$ of wear). The SGH was sent to the designer/engineer for repair, and the participant recommenced the trial later.

\subsection{Feasibility Outcomes}

This section focuses on issues that may inform the planning of future trials of newer models of the SGH (or other terminal devices for people with trans-radial limb difference).

\subsubsection{Recruitment and Retention}

We recruited nine participants (one/month) over the study period from a potentially eligible pool of 120 upper-limb prosthesis users (recruitment rate $=7.5 \%$ ). One participant withdrew from the study after fitting of the SGH (due to work/life demands and discomfort with the activity monitor); however, the remaining eight returned at the end of the trial and completed the interview and all Patient-Reported Outcome Measures (PROMs). Seven participants kept the SGH for the full two weeks, and one could only test it for one week due to international travel. Five completed the prosthesis wear diary; one partially completed it, and the others gave verbal reports.

\subsubsection{Acceptability, Reliability, and Data Retrieved from Activity Monitors}

The monitor on the intact arm was worn consistently for the entire recording period by only two participants. For one participant, the activity monitor on the SGH malfunctioned and did not record any data during the two-week trial. For the other seven, we found the monitor start times to be misaligned in 8/20 monitors, although for seven monitors 
(three participants) the misalignment was reasonably small (0.277-6.097 s). We also found the recording duration varied between monitors, with only 10/20 monitors recording for the full two weeks (NB: one participant (3 monitors) ended the study one week early). One possible explanation for these errors might relate to the battery charge on our monitors, as the researchers have previously collected data using Axivity monitors with no issues as part of other studies.

\section{Discussion}

To our knowledge, this is the first study to prospectively test a 3D-printed prototype hand with multiple users in a systematic manner, including measurement of actual wear time and bimanual activity over two weeks as well as consumer ratings of function and satisfaction. Recruitment was challenging during the nine-month study period, and we fell one short of our target of 10 on study closure. All but one participant completed the trial and returned for completion of all outcome measures, indicating that the study design and measures are likely to be feasible and acceptable to most consumers.

In our study, one-third of SGHs required repair or replacement. The need for repairs, however, indicates that participants were actively using them during the trial, as noted in Kyberd et al.'s survey of 156 upper-extremity prosthesis users [10]. This was supported by activity monitoring data, which showed $73-87 \%$ reliance on the anatomical arm across six participants, which is comparable to the upper-limb activity of myoelectric prosthesis users reported in Chadwell et al. [11].

Interpretation of our scores on the OPUS upper extremity function scale and TAPES-R is not possible, due to a lack of consistency in versions used and data reporting methods in previous papers [12-14]. We recommend that trials of future SGH models use the same measures, so that comparison to our data can give a relative indication of the merits of both devices. We also recommend that participants rate their usual prosthesis on these measures upon enrolment to the study, then rate the SGH after the two-week trial.

Mean scores on TAPES-R indicate that most participants were satisfied with both the appearance and function; however, the overall rating of 5/10 indicates considerable room for improvement.

Overall, our data suggest that the SGH may be acceptable and useful for people who prefer a cosmetic hand, but users of body-powered prostheses are unlikely to find them to be sufficiently functional.

Limitations and lessons learned before undertaking a large-scale study.

Participant recruitment from a single centre was challenging, and a larger planned within-subjects trial to compare data gathered over equivalent periods (usual prosthesis vs. SGH) would require a substantial recruitment period across multiple centres.

The SGH required repairs in about one-third of cases, and this would be unacceptable in a larger trial. Future designs must be more robust for those performing heavier tasks and should include more intuitive lock/unlock of grasp.

We had some equipment malfunctions and issues with fidelity to wearing the activity monitor on the intact limb, making data interpretation difficult at times. Two healthy volunteers tested monitors on both hands for a two-day period before this trial with no issues; however, we discovered that some of the other monitors were faulty only after participants completed the study. In future, we would recommend pre-trial calibration and testing of all activity monitors and securing these to the intact limb using waterproof dressings, as this has shown to be well-tolerated [15]. If persisting with the wristband, instructions should be clear about the need to wear it at all times, even when sleeping and training. Furthermore, instructions should be provided regarding how to put the wristband back on. 
There were several variables related to participant choice that are to be expected in a "real-world" study with participant autonomy. These included switching between terminal devices where necessary, for example, when driving or performing a work task. The most important variable in our opinion, and one which is rarely properly addressed in studies of upper-limb prostheses, is which device people choose to use in their everyday lives. As we placed monitors on both the SGH and their own prosthetic hand, using our non-wear algorithm [9] we were able to capture basic data on periods of use and non-use of each hand. The issue of whether or not people chose to wear a glove is common to all realworld studies of upper-limb prostheses and, also, rarely reported. It could be that a small sensor (lux meter) on the hand would offer such information, with little additional lab testing. Before the trial started, the team selected the most suitable commercially available cosmetic gloves. For future application, it would be desirable to have a cosmetic glove that is both very durable and compliant. Glove design is a problem common to all upper-limb prosthesis users and beyond the scope of this study.

\section{Materials and Methods}

We recruited a convenience sample of adults via Caulfield Hospital patient records and a closed online discussion group coordinated by Australia's leading amputee consumer association (Limbs4Life). Those who responded were included if they were current prosthesis users with trans-radial upper-limb absence and were available to attend the clinic and trial the prosthesis for 14 consecutive days. The recruitment period was March-December 2019. Participants provided written informed consent before commencing the study. The study was registered with Australian Therapeutic Goods Administration Clinical Device Trial prior to commencement (Ref: CT-2019-CTN-00998-1).

Protocol: Participants attended the prosthetics clinic, Caulfield Hospital, on at least two occasions for approximately one hour. During the first visit, the SGH and activity monitors were fitted; participants practiced common daily living tasks and then were advised to use the SGH in their home and work/study environments for two weeks. On their return visit, they completed two Patient Reported Outcome Measures and were interviewed regarding their experience with the SGH. The same occupational therapist (L.O.B.) conducted all semi-structured interviews, which began with asking about their experiences with the SGH, what activities they attempted to use it for (and how successful these were), what they liked or disliked about it, and any suggestions for improvement for future models.

Fitting process: The same prosthetist (E.M.) fitted the SGH to the wrist attachment of each individual's existing socket. A skin-coloured PVC prosthetic glove (model 8S11 from OttoBock, Germany) was applied where possible, but if the participant preferred the look or functionality of the hand without the glove, the hand was provided without it (see Figure 4). For two participants with passive prostheses, it was not possible to fit the SGH on the existing socket, and so a new socket was fabricated and fitted, requiring two additional one-hour clinic visits. Participants then practiced with the SGH (e.g., turning on taps, picking up a bottle/glass) with the prosthetist and occupational therapist present. 


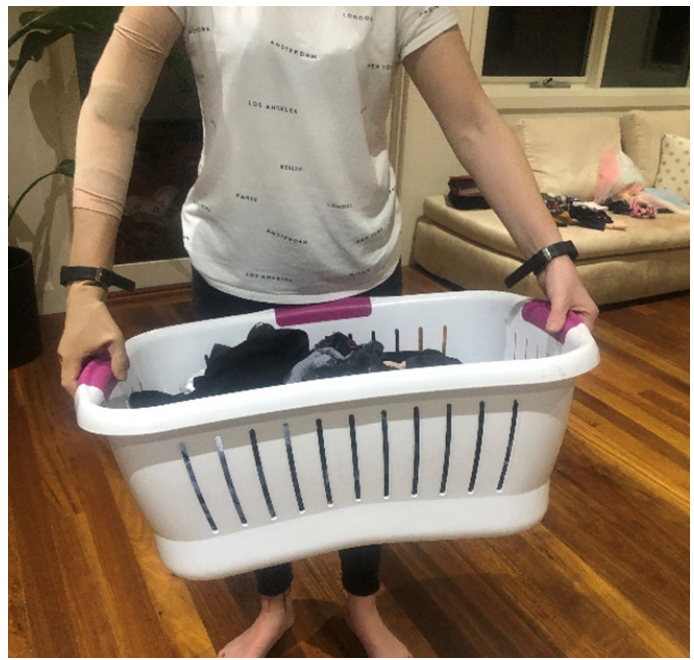

(a)

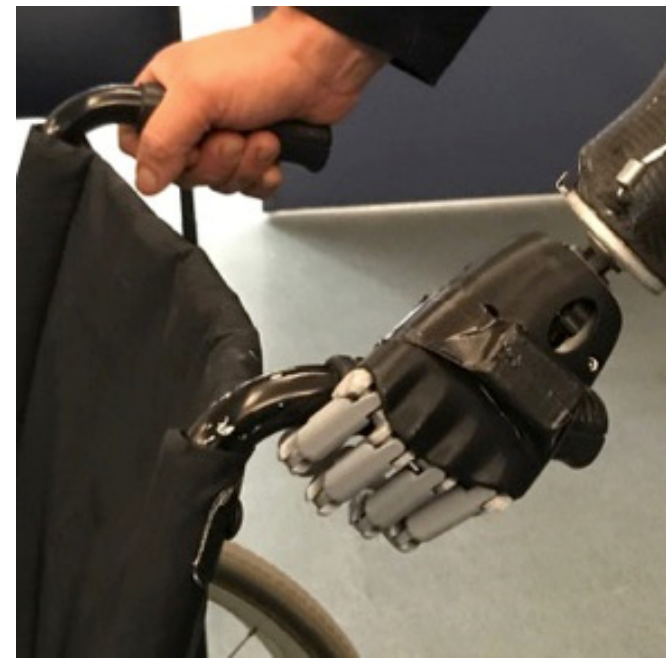

(b)

Figure 4. The Self Grasping Hand as fitted on participants (a) with glove; (b) without.

Participants were encouraged to use the SGH as much as possible for two weeks but were advised that they could interchange the SGH with their usual terminal device (body-powered split-hook or static cosmetic hand) if required to perform usual work or daily living activities.

\section{Objective measurement of prosthesis wear and use (Activity Monitoring):}

Axivity AX3 (Axivity, Newcastle, UK) monitors were fitted on each prosthetic hand and the anatomical wrist. These log data from their in-built three-axis accelerometers. For each participant, all monitors were initialised to begin recording at the same time and to record acceleration data at a sampling frequency of $50 \mathrm{~Hz}$ (dynamic range of $\pm 8 \mathrm{~g}$ ) for a period of two weeks. Silicone Axivity wristbands were provided for the anatomical wrist and, in cases where the SGH and cosmetic hand each had separate sockets, on the wrists of those sockets (Figure 2). In cases where the same socket was used for both the SGH and the participant's own prosthesis, the monitor was taped to the back of each hand (Figure 2) or, in the case of a hook, to the rigid proximal section just distal to the wrist connector. This avoided the participant forgetting to switch the monitors over when swapping between terminal devices.

Participants were requested to wear the monitors for the duration of the trial unless it became necessary to remove them, for example, when bathing or swimming. To aid interpretation of the accelerometer data, participants were asked to complete a diary detailing when they were wearing/not wearing each of the prostheses, when they were wearing/not wearing each of the individual monitors, and when they were asleep.

At the end of each participant's two-week trial period, data were downloaded from the monitors using proprietary OMGUI software (Github.com). Due to minor discrepancies in sampling rate on the monitors, resampling of the data was required (following instructions provided by Axivity); within the software, the data were resampled to $50 \mathrm{~Hz}$ and exported as .wav files for processing.

To allow the data to be analysed in a manner which was directly comparable to existing prosthesis-user data collected by Chadwell et al. [11,16], the acceleration signals from the Axivity monitors were converted into the equivalent of Actigraph (another commonly used accelerometer) activity counts with an epoch of $60 \mathrm{~s}$. Conversion was undertaken using methods developed by Brond et al. [17]. Data were then analysed using methods developed by Chadwell et al. [9]. Here, we report the wear time of each prosthesis, which was calculated automatically from the acceleration data using the non-wear algorithm published by Chadwell et al. [11,16]. We also calculated the percentage reliance on the intact arm for each $60 \mathrm{~s}$ epoch by dividing the vector magnitude of the activity counts recorded on the intact/dominant arm by the sum of the vector magnitude of the activity 
counts recorded across both arms. Here, we report the median percentage reliance on the intact arm for each prosthesis type [9].

\section{Patient Reported Outcome Measures:}

The PROMs used in this study were the Upper Extremity Functional Status module of the Orthotics and Prosthetics Users' Survey (OPUS) and the prosthesis satisfaction sub-scales of the Trinity Amputation and Prosthesis Experience Scales Revised (TAPES-R), which are summarized below. Participants had the opportunity of completing these at home prior to the final clinic appointment or doing these verbally with the occupational therapist at their final clinic visit. The OPUS enabled us to determine which daily living activities could be completed using the SGH and how easy/difficult it was to perform these. The TAPES-R enabled us to quantify participants' satisfaction with aesthetics and function of the SGH to inform priorities for future designs.

The Upper Extremity Functional Status (UEFS) module of the Orthotics and Prosthetics Users' Survey (OPUS) [18]: Participants were required to rate the ease of performing 23 self-care and instrumental daily living activities with the SGH. Responses were recorded on a 5-point rating scale: $0=$ cannot perform activity; $1=$ very difficult; 2 = slightly difficult; 3 = easy; 4 = very easy. Not applicable items were not scored. An additional question asked whether the SGH would usually be used when performing each activity. Frequency distribution and means are presented for scores on all 23 upper extremity functional status items. In addition, the sum of the scores for 23 items (0-92) was calculated and converted to Rasch measures ( $0-100$ scale) using the guide provided on the Shirley Ryan AbilityLab website [19]. Higher scores indicate greater function.

The prosthesis satisfaction sub-scales of the Trinity Amputation and Prosthesis Experience Scales Revised (TAPES-R) [20]: The TAPES-R measured satisfaction with SGH aesthetics (three items: colour, shape, appearance) and function (five items: weight, usefulness, reliability, fit, comfort) on a 3 -point scale $(1=$ not satisfied; $2=$ satisfied; 3 = very satisfied). Items within both sub-scales were summed and then averaged to give scores out of $3[21,22]$. The TAPES-R also includes a rating from $0-10$ for overall satisfaction with the prosthesis.

Feasibility measures:

To determine the feasibility of conducting future trials comparing the SGH with the participant's existing prosthesis, we collected data on:

- rates of recruitment over the nine-month study period, retention over the two-week trial period, and attendance at the follow-up appointment

- whether participants fully adhered to the study protocol, including testing the SGH at home and work over two weeks, completion of activity diaries and Patient Reported Outcome Measures (PROMs), and whether the activity monitors were worn as directed and performed reliably throughout the trial, and

- $\quad$ adverse events (e.g., breakages, malfunctions of prosthesis or activity monitor).

\section{Conclusions}

The SGH is a promising design for people who want a life-like hand with static grasp/release function; however, issues with durability of components and mechanisms, the release button, and the finger-to-thumb aperture need to be addressed in future models. Currently available cosmetic gloves have a limited durability. It would be desirable to have a cosmetic glove that is both durable and compliant. We also experienced equipment malfunctions and issues with fidelity to wearing the activity monitor on the intact limb and would recommend more thorough pre-trial calibration and testing of all activity monitors and securing these to the intact limb using waterproof dressings. Data obtained during this trial will inform the design, materials, and construction of future SGH versions, which will be tested using similar methodologies. 


\section{Patents}

The last author (G.S.) is one of the designers of the Self Grasping Hand and holds a patent (NL2015998B1).

Author Contributions: Conceptualization, L.O. and G.S.; methodology, L.O. and G.S.; software, A.C. and L.K.; data analysis, A.C.; investigation, L.O. and E.M.; data curation, A.C.; writing—original draft preparation, L.O.; writing-review and editing, G.S., A.C. and L.K.; visualization, A.C.; supervision, L.O., E.M. and G.S.; project administration, L.O.; funding acquisition, G.S. and L.O. All authors have read and agreed to the published version of the manuscript.

Funding: This research was funded by Promobilia Foundation, Sweden (Project Grant 18156).

Institutional Review Board Statement: The study was conducted according to the guidelines of the Declaration of Helsinki and approved by the Human Research and Ethics Committees of Monash University (Ref: 17829) 18 January 2019 and Alfred Health (Ref: 120/19) 5 April 2019.

Informed Consent Statement: Informed consent was obtained from all subjects involved in the study.

Data Availability Statement: All datasets are available in figshare (link to be provided on manuscript acceptance).

Acknowledgments: The authors sincerely thank Luuk Lommerse and Maaike Sinke, Master of Engineering students from TU Delft who completed three-month internships in Australia to assist with participant recruitment, device troubleshooting, and data collection.

Conflicts of Interest: G.S. is one of the designers of the Self Grasping Hand and patent holder for this device. All other author(s) declared no potential conflicts of interest with respect to the research, authorship, and/or publication of this article. The funders had no role in the design of the study; in the collection, analyses, or interpretation of data; in the writing of the manuscript, or in the decision to publish the results.

\section{References}

1. National Academies of Sciences Engineering and Medicine. The Promise of Assistive Technology to Enhance Activity and Work Participation; The National Academies Press: Washington, DC, USA, 2017.

2. Maat, B.; Smit, G.; Plettenburg, D.; Breedveld, P. Passive prosthetic hands and tools: A literature review. Prosthet. Orthot. Int. 2018, 42, 66-74. [CrossRef] [PubMed]

3. Burger, H.; Marinček, Č. Upper limb prosthetic use in Slovenia. Prosthet. Orthot. Int. 1994, 18, 25-33. [CrossRef] [PubMed]

4. Biddiss, E.; Beaton, D.; Chau, T. Consumer design priorities for upper limb prosthetics. Disabil. Rehabil. Assist. Technol. 2007, 2, 346-357. [CrossRef]

5. Soltanian, H.; De Bese, G.; Beasley, R.W. Passive hand prostheses. Hand Clin. 2003, 19, 177-183. [CrossRef]

6. Maat, B. Design and Evaluation of a New Passive Adjustable Prosthetic Hand Comprising a Novel Control Method. Master's Thesis, Delft University of Technology, Delft, The Netherlands, 2015.

7. Smit, G.; Maat, B.; Plettenburg, D.; Breedveld, P. A Self-Grasping Hand Prosthesis. In Proceedings of the Myoelectric Controls and Upper Limb Prosthetics Symposium, Fredericton, NB, Canada, 15-18 August 2017.

8. Chadwell, A.; Chinn, N.; Kenney, L.; Karthaus, Z.J.; Mos, D.; Smit, G. An evaluation of contralateral hand involvement in the operation of the Delft Self-Grasping Hand, an adjustable passive prosthesis. PLoS ONE 2021, 16, e0252870. [CrossRef]

9. Chadwell, A.; Kenney, L.; Granat, M.; Thies, S.; Head, J.S.; Galpin, A. Visualisation of upper limb activity using spirals: A new approach to the assessment of daily prosthesis usage. Prosthet. Orthot. Int. 2018, 42, 37-44. [CrossRef] [PubMed]

10. Kyberd, P.J.; Wartenberg, C.; Sandsjö, L.; Jönsson, S.; Gow, D.; Frid, J.; Almström, C.; Sperling, L. Survey of Upper-Extremity Prosthesis Users in Sweden and the United Kingdom. JPO J. Prosthet. Orthot. 2007, 19, 55-62. [CrossRef]

11. Chadwell, A.; Kenney, L.; Granat, M.H.; Thies, S.; Head, J.; Galpin, A.; Baker, R.; Kulkarni, J. Upper limb activity in myoelectric prosthesis users is biased towards the intact limb and appears unrelated to goal-directed task performance. Sci. Rep. 2018, 8 , 11084. [CrossRef] [PubMed]

12. Burger, H.; Franchignoni, F.; Heinemann, A.; Kotnik, S.; Giordano, A. Validation of the orthotics and prosthetics user survey upper extremity functional status module in people with unilateral upper limb amputation. J. Rehabil. Med. 2008, 40, 393-399. [CrossRef] [PubMed]

13. Deijs, M.; Bongers, R.M.; Ringeling-van Leusen, N.D.M.; Van Der Sluis, C.K. Flexible and static wrist units in upper limb prosthesis users: Functionality scores, user satisfaction and compensatory movements. J. Neuroeng. Rehabil. 2016, 13, 26. [CrossRef] [PubMed]

14. Resnik, L.; Borgia, M. Reliability and Validity of Outcome Measures for Upper Limb Amputation. JPO J. Prosthet. Orthot. 2012, 24, 192-201. [CrossRef] 
15. Schneller, M.B.; Bentsen, P.; Nielsen, G.; Brønd, J.C.; Ried-Larsen, M.; Mygind, E.; Schipperijn, J. Measuring children's physical activity: Compliance using skin-taped accelerometers. Med. Sci. Sports Exerc. 2017, 49, 1261-1269. [CrossRef]

16. Chadwell, A.; Kenney, L.; Granat, M.; Thies, S.; Galpin, A.; Head, J. Upper limb activity of twenty myoelectric prosthesis users and twenty healthy anatomically intact adults. Sci. Data 2019, 6, 199. [CrossRef] [PubMed]

17. Brønd, J.C.; Andersen, L.B.; Arvidsson, D. Generating ActiGraph Counts from Raw Acceleration Recorded by an Alternative Monitor. Med. Sci. Sports Exerc. 2017, 49, 2351-2360. [CrossRef]

18. Heinemann, A.W.; Bode, R.; O'Reilly, C. Development and measurement properties of the Orthotics and Prosthetics Users' Survey (OPUS): A comprehensive set of clinical outcome instruments. Prosthet. Orthot. Int. 2003, 27, 191-206. [CrossRef] [PubMed]

19. Shirley Ryan Ability Lab. OPUS UP Scoring Guide. Rehabilitation Measures Database 2016. Available online: https:/ /www.sralab. org/sites/default/files/2017-12/OPUS\%20UP\%20Scoring\%20Guide\%206\%20June\%202016.pdf (accessed on 12 December 2019).

20. Gallagher, P. Trinity Amputation and Prosthesis Experience Scales-Revised (TAPES-R). 2011. Available online: http: //psychoprosthetics.ie/assets/TAPES_2011_Sept_2011.pdf (accessed on 12 December 2019).

21. Gallagher, P.; Franchignoni, F.; Giordano, A.; MacLachlan, M. Trinity amputation and prosthesis experience scales: A psychometric assessment using classical test theory and rasch analysis. Am. J. Phys. Med. Rehabil. 2010, 89, 487-496. [CrossRef] [PubMed]

22. Heinemann, A.W.; Conelly, L.; Ehrlich-Jones, L.; Fatone, S. Outcome instruments for prosthetics: Clinical applications. Phys. Med. Rehabil. Clin. 2014, 25, 179-198. [CrossRef] [PubMed] 